\title{
Tác động của vốn con người đến phát triển tài chính ở Việt Nam
}

\section{The impact of human capital on financial development in Vietnam}

\author{
Nguyễn Minh Hà ${ }^{1}$, Nguyễn Đăng Hiễn ${ }^{1 *}$ \\ ${ }^{1}$ Trường Đại học Mở Thành phố Hồ Chí Minh, Việt Nam \\ *Tác giả liên hệ, Email: hien.nd@ou.edu.vn
}

\begin{tabular}{|c|c|}
\hline THÔNG TIN & TÓM TẮT \\
\hline $\begin{array}{l}\text { DOI:10.46223/HCMCOUJS. } \\
\text { econ.vi.16.2.1302.2021 }\end{array}$ & $\begin{array}{l}\text { Nghiên cứu được thực hiện nhằm tìm hiểu tác động của vốn } \\
\text { con người đến phát triển tài chính ở Việt Nam giai đoạn } 1990 \text { - } \\
\text { 2018. Vốn con người được đo lường thông qua tỷ lệ nhập học tiểu } \\
\text { học, sức khỏe của lao động, dân số lao động và biến kiềm soát thu } \\
\text { nhập bình quân đầu người. Phát triển tài chính được đo lường }\end{array}$ \\
\hline Ngày nhận: 02/11/2020 & thông qua tỷ lệ tín dụng nội địa cung cấp cho khu vực tư nhân. \\
\hline Ngày nhận lại: 11/12/2020 & $\begin{array}{l}\text { Nghiên cứu áp dụng mô hình phân phối trễ tự hồi quy (ARDL) để } \\
\text { đánh giá tác động trong ngắn hạn và dài hạn giữa vốn con người }\end{array}$ \\
\hline \multirow[t]{2}{*}{ Duyệt đăng: 28/12/2020 } & $\begin{array}{l}\text { và phát triển tài chính. Kết quả cho thấy các biến số của vốn con } \\
\text { người có tác động tích cực đến phát triển tài chính ở Việt Nam, } \\
\text { ngoại trừ dân số lao động có tác động ngược chiều. }\end{array}$ \\
\hline & ABSTRACT \\
\hline Tù khóa: & The study is conducted to investigate the impact of human \\
\hline $\begin{array}{l}\text { vốn con người; phát triển tài } \\
\text { chính }\end{array}$ & $\begin{array}{l}\text { capital on financial development in Vietnam, the period } 1990 \text { - } \\
\text { 2018. Human capital is measured through primary school } \\
\text { enrollment, worker health, the working population, and the } \\
\text { variable controlling GDP per capital. Financial development is } \\
\text { measured through domestic credit to the private sector. The study } \\
\text { applies Autoregressive Distributed Lag (ARDL) to assess the }\end{array}$ \\
\hline Keywords: & short and long-run impact between human capital and financial \\
\hline $\begin{array}{l}\text { human capital; financial } \\
\text { development }\end{array}$ & $\begin{array}{l}\text { development. The results show that the variables of human capital } \\
\text { positively impact financial development in Vietnam, except that } \\
\text { the working population has the opposite effect. }\end{array}$ \\
\hline
\end{tabular}

\section{Giới thiệu}

Để đánh giá sự phát triển toàn diện của một quốc gia hay cộng đồng thì rõ ràng các chỉ số kinh tế không phải là thước đo hoàn hảo. Vì tăng trưởng kinh tế chỉ mới phản ánh được một mặt của quá trình phát triển xã hội loài người, mà con người thì không chỉ bó hẹp trong quan hệ kinh tế và nhu cầu vật chất, con người còn có những nhu cầu khác như giáo dục, sức khỏe, các hoạt động xã hội... Xuất phát từ những điểm như vậy, các nhà khoa học đã nảy sinh ra cách thức tiếp cận mới về phát triển. Bao quát cho sự phát triển này đó chính là khái niệm vốn con người (T. D. Nguyen, 2014).

Theo Sehrawat và Giri (2017) sự phát triển của ngành tài chính và phát triển nguồn nhân lực là yếu tố quan trọng cho tăng trưởng kinh tế, điều mà bất kỳ một quốc gia nào cũng 
hướng đến. Ngược lại, lĩnh vực tài chính phát triển với nguồn nhân lực thấp dẫn đến tăng trưởng kinh tế thấp.

Theo báo cáo của IMF (2014) xem xét chỉ số phát triển tài chính của Việt Nam được xếp ở nhóm nước có chỉ số phát triển thị trường tài chính thấp nhất với 0.236 điểm, xếp thứ 95/183 nước trên thế giới. Theo Hatemi-J và Shamsuddin (2016) về mặt lý thuyết vốn con người có thể thúc đẩy phát triển tài chính thông qua việc thu hẹp lỗ hổng thông tin và nhu cầu ngày càng tăng đối với các công cụ tài chính khác nhau. Ngoài ra, phát triển tài chính được coi là quan trọng như vốn con người trong việc góp phần vào tăng trưởng kinh tế.

Vai trò của ngành tài chính trong nền kinh tế đã trở nên dễ bị tổn thương hơn sau cuộc khủng hoảng tài chính toàn cầu năm 2008. Một số loại lý thuyết và thực nghiệm của các nghiên cứu đã được thực hiện về phát triển nguồn nhân lực và phát triển tài chính sau cuộc khủng hoảng này là khá nhiều, như nghiên cứu của Nik, Zahra, Yunes, và Nima (2013) về mối quan hệ giữa vốn con người và phát triển tài chính ở Iran, nghiên cứu của Satrovic (2017) về phát triển tài chính và vốn con người ở Thổ Nhĩ Kỳ hay công trình của Giri (2014) về vốn con người và phát triển tài chính ở Ân Độ... tuy nhiên đối với Việt Nam hiện còn rất ít công trình nghiên cứu về mối quan hệ giữa hai biến số này.

Vì vậy, nghiên cứu hiện tại nhằm mục đích kiểm tra và đánh giá được tác động của vốn con người đến phát triển tài chính ở Việt Nam qua đó nhằm gợi mở những chính sách để nâng cao vốn con người đối với sự phát triển tài chính ở Việt Nam hiện nay.

\section{Cơ sở lý thuyết}

\subsection{Vốn con người và đo lường vốn con ngưòi}

Theo Schultz (1961) đã khởi đầu cho sự quan tâm đến khái niệm vốn con người, ông cho rằng yếu tố hình thành nên vốn con người là kỹ năng và tri thức mà họ thu nhận được. Theo Laroche, Mérette, và Ruggeri (1999) vốn con người có ba đặc điểm: (i) vốn con người là hàng hóa bất khả thương; (ii) vốn con người vừa mang tính cá nhân, vừa mang tính cộng đồng; (iii) vốn con người có cả lượng và chất.

Theo Becker và Murphy (2009) vốn con người là kỹ năng và kiến thức mà cá nhân có được thông qua đầu tư vào đi học, đào tạo tại chỗ và các loại kinh nghiệm khác, nó tương tự như phương tiện sản xuất của vật chất như máy móc và nhà máy. Lý thuyết vốn con người không giải thích quá trình chuyển giao vốn nhân lực. Lý thuyết đơn giản chỉ ra rằng đầu tư vào vốn nhân lực để cải thiện kiến thức, kỹ năng hoặc sức khỏe nhờ đó giúp tăng thu nhập.

Vốn con người có thể được phát triển thông qua đào tạo và giáo dục chính thức nhằm bổ sung và cập nhật khả năng để cá nhân làm tốt hơn trong xã hội. Các nhà nghiên cứu trước đây có phân biệt giữa các loại vốn nhân lực khác nhau (Florin \& Schultze, 2000).

Có khá nhiều các nghiên cứu cũng như những kết luận về vốn con người, tuy nhiên tựu trung lại, vốn con người có đặc điểm như sau: có thể được đầu tư thông qua giáo dục, đào tạo, chăm sóc y tế và thu nhập của loại vốn này cũng tùy thuộc vào số lượng vốn mà cá nhân sở hữu. Kế thừa từ những nghiên cứu đi trước trên thế giới cũng như tại Việt Nam, nghiên cứu này xem xét tác động của vốn con người thông qua yếu tố chính là giáo dục.

\section{Đo lường vốn con người}

Có khá nhiều các nghiên cứu khác nhau về vốn con người, các nghiên cứu kinh tế cố gắng tiếp cận các khía cạnh khác nhau của vốn con người như dựa trên giáo dục, chi phí giáo dục hay thu nhập của lao động nhằm xây dựng nhiều thước đo vốn con người như tỷ lệ người biết 
chữ, tỷ lệ nhập học các cấp, tỷ lệ học sinh - giáo viên, chi phí giáo dục.

Theo K. D. Nguyen (2013) có các cách đo lường vốn con người như: tỷ lệ nhập học các cấp bậc giáo dục, số năm đi học bình quân của lao động, chi phí giáo dục và thu nhập của lao động.

Trong nghiên cứu của Dinh và Tu (2016) tác giả đo lường vốn con người thông qua các biến: số năm đi học bình quân đầu người của lực lượng lao động, chi tiêu ngân sách nhà nước cho giáo dục và y tế. Kết quả của nghiên cứu chỉ ra sự ảnh hưởng của vốn con người đến tăng trưởng kinh tế Đồng bằng Sông Cửu Long thông qua các chỉ tiêu đo lường vốn con người như trên.

Tuy nhiên, theo Tran (2014) cách tiếp cận về giáo dục để đo lường vốn con người có vẻ bao quát và phản ánh đầy đủ hơn về bản chất vốn con người. Theo đó, cách tiếp cận này ước tính vốn con người đo lường các chỉ tiêu về giáo dục như tỷ lệ biết chữ, tỷ lệ đi học, số năm đi học trung bình. Tính hợp lý của phương pháp này là các chỉ số trên có liên quan đến đầu tư cho giáo dục và đó là yếu tố cơ bản trong việc hình thành vốn con người. Các chỉ tiêu về giáo dục là các đại diện cho vốn nhân lực chứ không phải là các chỉ tiêu đo lường trực tiếp.

Theo Nafziger (2006) trường học đưa ra kiến thức cụ thể, phát triển các kỹ năng lý luận chung, làm thay đổi các giá trị, tăng khả năng tiếp thu các ý tưởng mới và thay đổi thái độ đối với công việc và xã hội. Vì vậy, có thể suy ra rằng giáo dục là một thế mạnh công cụ để thực thi vốn con người và được xem là một yếu tố quan trọng trong sản xuất.

Cũng nhận định về vốn con người, tuy nhiên ở phạm vi rộng hơn Hakeem và Oluitan (2012) cho rằng tích lũy vốn con người thường được phân tách vốn con người vào cả vốn nhân lực trong giáo dục và vốn nhân lực sức khỏe. Hai loại vốn con người như vậy đã được tìm thấy có tác động khác nhau và cơ chế truyền dẫn về tăng trưởng và phát triển.

Kế thừa từ những nghiên cứu đi trước, nhằm khái quát vốn con người ở Việt Nam, đề tài này đo lường vốn con người thông qua yếu tố giáo dục và sức khỏe của lao động. Giáo dục trong phạm vi của nghiên cứu sẽ đo lường thông qua tỷ lệ nhập học tiểu học. Theo định nghĩa World bank tỷ lệ nhập học tiểu học là tỷ lệ giữa tổng số dân nhập học không phân biệt tuổi, so với dân số trong độ tuổi chính thức tương ứng với trình độ học vấn được thể hiện. Giáo dục tiểu học cung cấp cho trẻ em các kỹ năng đọc, viết cơ bản cùng với những kiến thức sơ đẳng về các môn học tự nhiên và xã hội. Tuổi thọ của dân số là tuổi thống kê mà một người dự kiến sẽ sống đến lúc đó dựa trên tính toán của chuyên gia. Số lượng lao động được xem xét đại diện cho lực lượng dân số trong độ tuổi lao động. Đây cũng là cách đo lường được sử dụng trong các nghiên cứu của Arif và Khan (2019); Awan và Kamran (2017); Bardi và Ayouni (2016); Hakeem và Oluitan (2012); Sehrawat và Giri (2017).

\subsection{Lý thuyết phát triển tài chính và đo luờng phát triển tài chính}

Theo World Bank (2014), phát triển tài chính là trạng thái đạt được khi các công cụ tài chính, thị trường tài chính và các trung gian tài chính làm giảm bớt (không loại bỏ) các hiệu ứng của thông tin không hoàn hảo, hạn chế trong thực thi hợp đồng và các chi phí giao dịch.

Theo Merton và Bodie (1995) xem phát triển tài chính là một quá trình thành lập các định chế nhằm mục đích tăng cơ sở thông tin, tăng cường khả năng phân tích của hệ thống tài chính và đáp ứng các nhu cầu mới của nhà kinh doanh, hộ gia đình, thông qua việc đa dạng hóa các loại công cụ, hợp đồng tài chính. Rõ ràng, nhận định này mang tính trực diện hơn, rõ hơn về khái niệm phát triển tài chính. Trong khi đó, định nghĩa phát triển tài chính được Diễn đàn Kinh tế Thế giới giải thích như sau World Bank (2014) phát triển tài chính được định nghĩa là các yếu tố, 
chính sách và thể chế nhằm tạo ra các thị trường và trung gian tài chính hiệu quả, cũng như khả năng tiếp cận vốn và các dịch vụ tài chính sâu và rộng. Cũng trong khái niệm này, có 07 chiều cạnh phát triển tương ứng với trụ cột của phát triển tài chính được đưa ra, bao gồm: (i) môi trường thể chế; (ii) môi trường kinh doanh; (iii) sự ổn định tài chính; (iv) các dịch vụ tài chính ngân hàng; (v) các dịch vụ tài chính phi ngân hàng; (vi) các thị trường tài chính và (vii) tiếp cận tài chính.

Trong bài nghiên cứu, việc đo lường phát triển tài chính được sử dụng thông qua tỷ lệ tín dụng nội địa cho khu vực tư nhân. Đây cũng là chỉ số được các nghiên cứu trước sử dụng phổ biến như Awan và Kamran (2017); Hakeem và Oluitan (2012); Sehrawat và Giri (2017).

\subsection{Mối quan hệ giữa tỷ lệ nhập học tiểu học và phát triển tài chính}

Theo Sethi, Mishra, và Bhujabal (2019) tỷ lệ đăng ký nhập học tiểu học (tính theo phần trăm tổng dân số) bất kể tuổi tác, dân số của nhóm tuổi chính thức tương ứng với trình độ học vấn thể hiện. Giáo dục tiểu học cung cấp cho trẻ kỹ năng cơ bản như đọc, viết, những sự hiểu biết cơ bản về toán học, các môn học về khoa học xã hội, khoa học tự nhiên hay về âm nhạc, nghệ thuật. Trong nghiên cứu này, các tác giả cũng xác định mối quan hệ đồng biến giữa tỷ lệ nhập học tiểu học và biến phụ thuộc là chỉ số phát triển tài chính tăng 01 phần trăm chỉ số phát triển tài chính làm tăng vốn con người thông qua tỷ lệ đăng ký nhập học tiểu học bằng $0.003 \%$. Cũng đo lường cho vốn con người trong nghiên cứu của mình Hakeem và Oluitan (2012) đã sử dụng tổng hợp các chỉ số về tỷ lệ đăng ký nhập học tiểu học, trung học và cao đẳng đại học để dại diện đo lường cho vốn con người ở Nam Phi. Nhóm tác giả đã nhấn mạnh tầm quan trọng của vốn con người trong mối liên hệ với phát triển tài chính trong cả ngắn hạn và dài hạn. Ngoài ra, các nghiên cứu của Sehrawat và Giri (2017) cũng tìm thấy mối liên hệ mạnh mẽ giữa vốn con người mà đại diện là tỷ lệ đăng ký nhập học tiểu học và phát triển tài chính ở một số quốc gia Châu Á được tác giả lựa chọn trong nghiên cứu của mình.

Giả thuyết H1: Tỷ lệ đăng ký nhập học tiểu học có tác động đồng biến với mức độ ảnh hưởng đến sự phát triển tài chinh

\subsection{Mối quan hệ giữa tuổi thọ lao động và phát triển tài chính}

Theo Hakeem và Oluitan (2012) tuổi thọ dân số có mối tương quan chặt chẽ với văn hóa tiết kiệm và vay mượn của nhiều người. Một cá nhân có nguy cơ tử vong thấp hay sức khỏe mạnh có khả năng phản ứng nhanh hơn với sự phát triển của ngành tài chính hơn là một người yếu hoặc ai đó có sức khỏe kém, người có khả năng thanh toán tất cả dịch vụ y tế của mình. Nhóm tác giả cũng xác định tuổi thọ trung bình của lao động tăng sẽ hữu ích hơn cho cả vốn con người và cho cả sự phát triển tài chính và tăng trưởng kinh tế. Bởi vì tăng tuổi thọ của lao động sẽ giúp quá trình sản xuất của nguồn nhân lực cho cả lĩnh vực tài chính nói riêng và kinh tế nói chung đều sẽ tăng theo. Trong nghiên cứu về tác động của vốn con người đến tăng trưởng kinh tế Pakistan, tác giả Awan và Kamran (2017) cũng khẳng định trong ngắn hạn và dài hạn tuổi thọ của lao động có tác động lớn đến tăng trưởng kinh tế của Pakistan, thậm chí các tác giả còn nhận định khi tăng một đơn vị tuổi thọ của lao động thì mức tăng trưởng GDP tăng 0.25 đơn vị và có ý nghĩa trong dài hạn.

Trong nghiên cứu này, biến tuổi thọ trung bình của lao động được kế thừa để nghiên cứu và phản ánh sức khỏe của lao động, hay phản ánh khía cạnh sức khỏe trong vốn con người nói chung.

Giả thuyết H2: Tuổi thọ của dân số có tác động đồng biến với phát triển tài chính 


\subsection{Biến dân số lao động}

Trong nghiên cứu của Arif và Khan (2019) về phát triển tài chính và phát triển vốn con người ở Pakistan, tác giả đã xác nhận rằng dân số lao động tăng lên sẽ dẫn đến sự phát triển về vốn con người ít hơn. Lý giải thêm cho vấn đề này, tác giả lưu ý khi phát triển tài chính dư thừa tiền và tạo ra trung gian tài chính hiệu quả giữa người cho vay và người vay, điều này làm ảnh hưởng đến sự phát triển vốn con người và cuối cùng là nền kinh tế Pakistan. Theo World Bank định nghĩa tổng dân số trong độ tuổi từ 15 - 64. Dân số dựa trên thực tế tính tất cả cư dân và quốc tịch khác. Biến này được tác giả đo lường qua số lượng lao động, dữ liệu được thu thập từ World bank và được lấy Logarit.

Giả thuyết H3: Dân số lao động có tác động đồng biến đến phát triển vốn con người và phát triển tài chính

\subsection{Thu nhập bình quân đầu người}

Trong nghiên cứu của Giri (2014) tìm hiểu về mối quan hệ giữa phát triển tài chính và vốn con người của Ấn Độ đã cho thấy mức độ ảnh hưởng của biến tăng trưởng kinh tế và tầm quan trọng của nó. Kết quả thực nghiệm của nghiên cứu cho thấy chỉ số vốn con người HDI giải thích được sự tăng lên theo thời gian thông qua biến tăng trưởng kinh tế ở năm thứ hai với $7.17 \%$ phần trăm thay đổi biến phát triển con người được giải thích bằng biến phát triển tài chính. Công trình của Kilic và Ozcan (2018) khi tìm hiểu về tác động của phát triển tài chính đối với vốn con người ở các nền kinh tế mới nổi đã chỉ ra rằng phát triển tài chính và tăng trưởng kinh tế ảnh hưởng tích cực đến vốn con người. Thậm chí, tăng trưởng kinh tế có tác động cao hơn đến vốn con người so với biến phát triển tài chính.

Ngoài ra, nhiều công trình nghiên cứu khác nhau về chủ đề vốn con người, phát triển tài chính của các tác giả Awan và Kamran (2017) hay Sethi và cộng sự (2019) đều nhìn nhận tầm quan trọng và mức độ ảnh hưởng của biến tăng trưởng kinh tế được xem là biến kiểm soát tính hiệu quả của nền kinh tế.

Dữ liệu của biến này được thu thập từ dữ liệu của World bank và được lấy Logarit để phù hợp.

Giả thuyết H4: GDP bình quân đầu người có tác động dương đến vốn con người và múc độ phát triển tài chính

\section{Thiết kế nghiên cứu}

\subsection{Phương pháp nghiên cúu}

Để xem xét tác động của vốn con người đến phát triển tài chính ở Việt Nam, nghiên cứu sử dụng mô hình phân phối trễ tự hồi quy (Autoregressive Distributed Lag: ARDL) được đề xuất bởi Pesaran, Shin, và Smith (1996). Đây được coi là sự kết hợp giữa mô hình tự hồi quy vector (VAR) và mô hình hồi quy bình phương nhỏ nhất (OLS). Theo Sehrawat và Giri (2014) mô hình ARDL được xem là phù hợp và có nhiều ưu điểm để phân tích thực nghiệm mối quan hệ lâu dài giữa các biến số kinh tế như sau: (i) Đầu tiên là kiểm định ràng buộc đơn giản so với kỹ thuật hợp nhất đa biến của Johansen và Juselius (1990), kỹ thuật này cho phép xem xét mối quan hệ đồng tích hợp được ước tính bằng OLS một khi xác định được độ trễ. (ii) Quy trình kiểm tra ràng buộc không yêu cầu kiểm tra trước các biến bao gồm trong mô hình cho đơn vị gốc như các kỹ thuật khác như của Engle và Granger (1987) và Johansen (1992), phương pháp này có thể thực hiện với các biến có độ trễ khác nhau, không phân biệt thứ tự sai phân $\mathrm{I}(0), \mathrm{I}(1)$, hoặc cả hai. (iii) Uu điểm thứ ba của việc sử dụng mô hình này chính là tính hiệu quả hơn trong trường hợp kích 
thước dữ liệu mẫu nhỏ và hữu hạn như trong nghiên cứu này. (iv) Tính toán trong ngắn hạn với ước lượng hiệu chỉnh sai số $(\mathrm{ECM})$ bằng biến đổi tuyến tính mà không làm mất bậc tự do (Pesaran, Shin, \& Smith, 2001).

\subsection{Mô hình nghiên cúu}

Kế thừa từ các nghiên cứu của Arif và Khan (2019); Khan, Hussain, Shabaz, Yang, và Jiao (2020), Satrovic (2017), Kilic và Ozcan (2018), Nik, Nasab, Salmani, và Shahriari (2013) và Sehrawat và Giri (2014), mô hình nghiên cứu tác động của vốn con người đến phát triển tài chính ở Việt Nam có dạng tổng quát sau:

$F D=f(F R I M, L I F E, P O P U, G D P$,$) Trong đó: FD: là biến phụ thuộc phát triển tài$ chính, FRIM: biến độc lập tỷ lệ đăng ký nhập học tiểu học, LIFE: tuổi thọ trung bình của lao động, POPU: số lượng lao động, GDP: Biến kiểm soát về thu nhập bình quân đầu người

Mô hình ARDL tổng quát cho nghiên cứu này như sau:

$$
\begin{aligned}
& \Delta F D=\alpha_{0}+\gamma_{1} F D_{t-i}+\gamma_{2} F_{R I M} M_{-i}+\gamma_{3} L_{F} F E_{t-i}+\gamma_{4} P O P U_{t-i}+\gamma_{5} G D P_{t-i}+ \\
& \sum_{k=1}^{a} \beta_{k 1} \Delta F D_{t-i}+\sum_{l=1}^{b} \beta_{l 1} \Delta F R I M_{t-i}+\sum_{m=1}^{c} \beta_{m 1} \Delta L I F E_{t-i}+\sum_{n=1}^{d} \beta_{n 1} \Delta P O P U_{t-i}+ \\
& \sum_{q=1}^{e} \beta_{q 1} \Delta G D P_{t-i}+\varepsilon_{t}
\end{aligned}
$$

\subsection{Trình tự phân tích mô hình}

Theo Pesaran và cộng sự (1996) thủ tục chạy mô hình ARDL được tiến hành như sau:

Thứ nhất, kiểm định đường bao (Bound test) xác định đồng liên kết giữa các biến, tức là tìm mối quan hệ dài hạn giữa các biến

Thứ hai, xác định độ trễ của các biến trong mô hình ARDL bằng tiêu chí SBC (Schwarz Bayesia Information Criterion) hoặc AIC (Akaike Information Criterion);

Thứ ba, chạy mô hình ARDL với các độ trễ đã được xác định để kiểm định mối quan hệ dài hạn giữa các biến trong mô hình

Thứ tư, tính tác động ngắn hạn của các biến bởi mô hình hiệu chỉnh sai số (ECM) dựa trên cách tiếp cận ARDL đối với đồng liên kết.

\section{Kết quả nghiên cứu}

\subsection{Thống kê mô tả}

Theo Bảng 1, dữ liệu được thống kê mô tả từ dữ liệu gốc, dữ liệu theo chuỗi thời gian, số liệu thu thập theo năm từ 1990 - 2018, gồm 29 quan sát. Giá trị phát triển tài chính (FD) có giá trị lớn nhất 133.1360 vào năm 2018, giá trị nhỏ nhất 13.65691 vào năm 1992 , giá trị trung bình là 62.55523 .

Đối với biến tỷ lệ nhập học tiểu học (PRIM) giá trị lớn nhất 115.7248 năm 1997, giá trị nhỏ nhất 97.72135 vào năm 2005, giá trị trung bình là 107.3137 .

Biến tuổi thọ dân số (LIFE) cao nhất 75.317 năm 2018, giá trị thấp nhất 70.551 năm 1990, giá trị trung bình của biến tuổi thọ dân số 73.53672 .

Biến số lượng lao động (POPU) giá trị cao nhất 66,450,585 vào năm 2018, giá trị nhỏ nhất 38,752,592 vào năm 1990, giá trị trung bình của biến số lượng lao động 53,911,518.

Biến GDP bình quân đầu người giá trị cao nhất 2,566.597 vào năm 2018, giá trị thấp nhất 95.18825 năm 1990, giá trị trung bình 935.8063. 


\section{Bảng 1}

Thống kê mô tả các biến trong mô hình

\begin{tabular}{|l|c|c|c|c|c|}
\hline & FD & PRIM & LIFE & POPU & GDP \\
\hline Trung bình & 62.55523 & 107.3137 & 73.53672 & $53,911,518$ & 935.8063 \\
\hline Trung vị & 58.72243 & 107.7544 & 73.87500 & $54,367,249$ & 546.9096 \\
\hline Giá trị lớn nhất & 133.1360 & 115.7248 & 75.31700 & $66,450,585$ & $2,566.597$ \\
\hline Giá trị nhỏ nhất & 13.65691 & 97.72135 & 70.55100 & $38,752,592$ & 95.18825 \\
\hline Độ lệch chuẩn & 41.36292 & 5.245992 & 1.504329 & $9,107,488$ & 782.0435 \\
\hline Hệ số bất đối xứng & 0.262420 & -0.332996 & -0.516761 & -0.149169 & 0.730565 \\
\hline Hệ số nhọn & 1.576910 & 2.087334 & 1.944112 & 1.651526 & 2.093299 \\
\hline Jarque-Bera & 2.779941 & 1.542444 & 2.637872 & 2.304761 & 3.573048 \\
\hline Tổng & $1,814.102$ & $3,112.098$ & $2,132.565$ & $15,634,340$ & $27,138.38$ \\
\hline Tổng bình phương chênh lệch & $47,904.96$ & 770.5720 & 63.36419 & $23,224,976$ & $17,124,578$ \\
\hline Số quan sát & 29 & 29 & 29 & 29 & 29 \\
\hline
\end{tabular}

Nguồn: Tác giả tổng hợp từ EVIEWS

\subsection{Kiểm định tính dùng}

Theo Gujarati (2003), trong phân tích hồi quy với dữ liệu chuỗi thời gian, một giả định rất quan trọng là chuô̂i thời gian đang xem xét là chuô̂i dừng (stationary). Trong nghiên cứu này, tác giả sử dụng phương pháp $\mathrm{ADF}$ mở rộng của Dickey và Fuller (1981) để kiểm định tính dừng các biến trong mô hình.

\section{Bảng 2}

Kết quả kiểm định tính dừng các biến của mô hình

\begin{tabular}{|l|c|c|c|c|c|}
\hline \multicolumn{1}{|c|}{ Tên biến } & $\begin{array}{c}\text { Kết quả } \\
\text { kiểm định } \\
\text { ADF }\end{array}$ & $\begin{array}{c}\text { Giá trị thống } \\
\text { kê t ớ mức ý } \\
\text { nghĩa 1\% }\end{array}$ & $\begin{array}{c}\text { Giá trị thống } \\
\text { kê t ớ mức ý } \\
\text { nghĩa 5\% }\end{array}$ & $\begin{array}{c}\text { Giá trị thống } \\
\text { kê t ớ mức ý } \\
\text { nghĩa 10\% }\end{array}$ & Xác suất \\
\hline FD & 0.474710 & -3.689194 & -2.971853 & -2.625121 & 0.9826 \\
\hline DFD & -4.555812 & -3.699871 & -2.976263 & -2.627420 & 0.0013 \\
\hline PRIM & -2.046876 & -3.752946 & -2.998064 & -2.638752 & 0.2663 \\
\hline DPRIM & -3.731052 & -3.752946 & -2.998064 & -2.638752 & 0.0105 \\
\hline LIFE & -2.174666 & -3.752946 & -2.998064 & -2.638752 & 0.2200 \\
\hline DLIFE & -3.823558 & -4.467895 & -3.644963 & -3.261452 & 0.357 \\
\hline LnPOPU & -2.606162 & -3.769597 & -3.004861 & -2.642242 & 0.1068 \\
\hline DlnPOPU & -5.591176 & -4.356068 & -3.595026 & -3.233456 & 0.0006 \\
\hline LnGDP & -1.264426 & -3.699871 & -2.976263 & -2.627420 & 0.6309 \\
\hline DlnGDP & -5.485985 & -3.699871 & -2.976263 & -2.627420 & 0.0001 \\
\hline
\end{tabular}

Nguồn: Tác giả tổng hợp từ EVIEWS 
Với các kết quả kiểm định như trong Bảng 2 có thể thấy các chuỗi dữ liệu gốc đều là chuỗi không dừng, tuy nhiên khi lấy sai phân đều là chuỗi dừng sai phân bậc 1 với các mức ý nghĩa $1 \%, 5 \%$ hay $10 \%$.

Việc xác định được các chuỗi dữ liệu là dừng sai phân bậc 1 đủ điều kiện để thực hiện hồi quy theo mô hình ARDL.

\subsection{Xác định độ trễ (lag) tối uu trong mô hình ARDL}

Độ trễ tối ưu được lựa chọn dựa theo tiêu chuẩn AIC, SIC hay HQ. Đề tài ước lượng mô hình ARDL bằng phần mềm EVIEWS với độ trễ tối ưu được lựa chọn theo tiêu chuẩn AIC. Theo Hình 1 độ trễ tối ưu được lựa chọn là (ARDL 1, 0, 2, 2, 0).

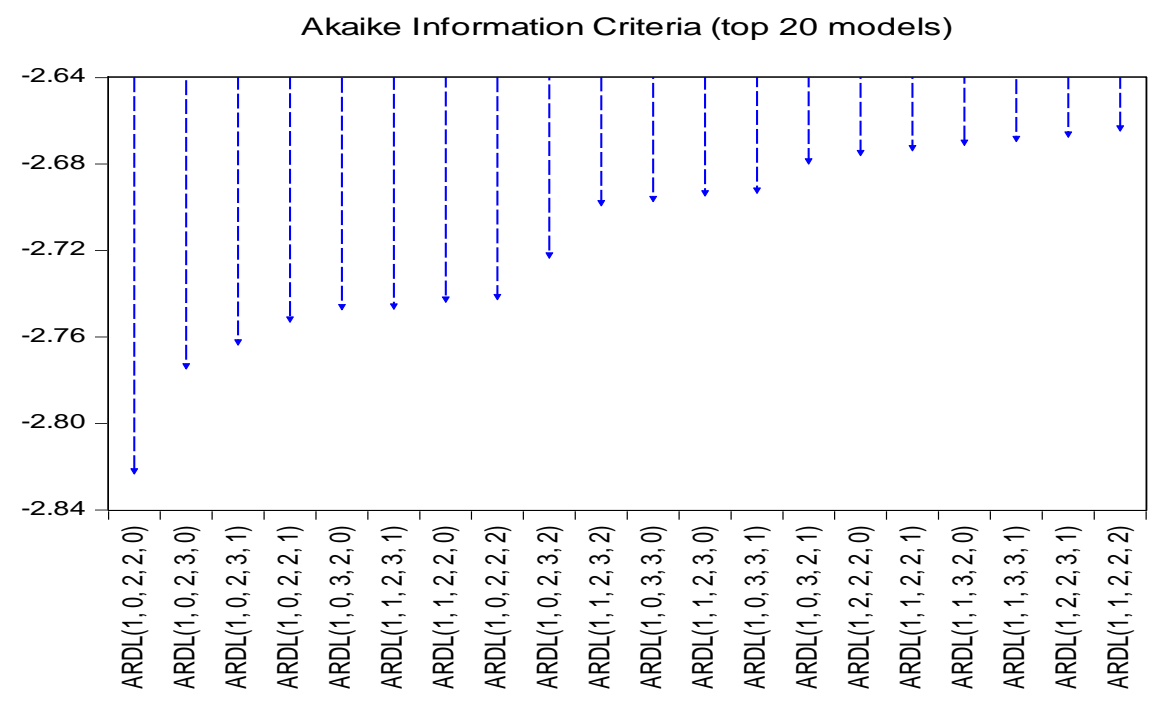

Hình 1. Lựa chọn độ trễ tối ưu

Nguồn: Tác giả tổng hợp từ EVIEWS

\subsection{Kiểm định đồng liên kết và mối quan hệ dài hạn}

Theo Pesaran và cộng sự (1996) phương pháp kiểm định đường bao (Bound test) xác định đồng liên kết giữa các biến, cũng có nghĩa rằng đi tìm mối quan hệ dài hạn giữa các biến. Trong nghiên cứu này, tác giả vận dụng kiểm định Bound test để kiểm định hiện tượng đồng liên kết với giả thuyết như sau:

\section{Bảng 3}

Kết quả kiểm định đồng liên kết của mô hình

\begin{tabular}{|l|c|c|c|c|}
\hline \multicolumn{2}{|c|}{ F-Bounds Test } & \multicolumn{3}{c|}{ Null Hypothesis: No levels relationship } \\
\hline Test Statistic & Value & Signif. & $\mathrm{I}(0)$ & $\mathrm{I}(1)$ \\
\hline & & & Asymptotic: $\mathrm{n}=1000$ & \\
\hline F-statistic & 15.10060 & $10 \%$ & 2.45 & 3.52 \\
\hline $\mathrm{k}$ & 4 & $5 \%$ & 2.86 & 4.01 \\
\hline & & $2.5 \%$ & 3.25 & 4.49 \\
\hline & & $1 \%$ & 3.74 & 5.06 \\
\hline
\end{tabular}

Nguồn: Tác giả tổng hợp từ EVIEWS 
Theo kết quả kiểm định trong Bảng 3 giá trị F-statistic $=15.10060$ đều lớn hơn cả 04 mức tới hạn đường bao ứng với 04 mức ý nghĩa $10 \%, 5 \%, 2.5 \%$ và $1 \%$. Như vậy giả thuyết $\mathrm{H}_{0}$ bị bác bỏ, chấp nhận giả thuyết $\mathrm{H}_{1}$. Do đó, chấp nhận mô hình có hiện tượng đồng liên kết giữa các biến, hay nói theo cách khác là tồn tại mối quan hệ dài hạn giữa các biến độc lập với biến phụ thuộc.

\section{Bảng 4}

Tác động dài hạn của các biến

\begin{tabular}{|l|c|c|c|c|}
\hline Tên biến & Hệ số hồi quy & Sai số chuẩn & Thống kê t & Xác suất \\
\hline DPRIM & 2.119680 & 0.850311 & 2.492831 & 0.0240 \\
\hline DLIFE & 0.124845 & 0.040839 & 3.057013 & 0.0075 \\
\hline DLNPOPU & -3019.670 & 887.6904 & -3.401715 & 0.0036 \\
\hline DLNGDP & 54.29059 & 13.59927 & 3.992169 & 0.0010 \\
\hline
\end{tabular}

Nguồn: Tác giả tổng hợp từ EVIEWS

Theo Bảng 4 trong dài hạn biến tỷ lệ nhập học tiểu học DPRIM có hệ số dương và có ý nghĩa thống kê. Điều này cho thấy trong dài hạn tỷ lệ nhập học tiểu học có tác động dương đến phát triển tài chính của Việt Nam. Điều này khá phù hợp với kỳ vọng ban đầu cũng như các lý thuyết nền về vốn con người và phát triển tài chính mà vốn con người thường được các tác giả đo lường thông qua tỷ lệ nhập học tiểu học như Sehrawat và Giri (2017), Hakeem và Oluitan (2012).

Tương tự, biến tuổi thọ dân số DLIFE cũng có hệ số hồi dương và có ý nghĩa thống kê. Kết quả này thể hiện trong dài hạn mối quan hệ giữa tuổi thọ lao động có ảnh hưởng tích cực đến phát triển tài chính. Theo Awan và Kamran (2017), trong dài hạn tuổi thọ của người dân Pakistan nếu gia tăng 0.25 đơn vị thì ảnh hưởng đến phát triển tài chính một đơn vị. Với kết quả trong Bảng 4 có thể thấy trường hợp của Việt Nam cũng khá tương đồng như vậy, khi hệ số hồi quy của biến tuổi thọ dân số là 0.124 và có ảnh hưởng trong dài hạn với phát triển tài chính.

Đối với biến DLNPOPU có hệ số hồi quy âm tức có tác động ngược chiều đến phát triển tài chính và có ý nghĩa thống kê. Kết quả này phù hợp với giả thuyết ban đầu tác giả đưa ra. Theo nhận thức của tác giả, đối với biến dân số lao động và GDP bình quân đầu người của Việt Nam có tác động âm đến phát triển tài chính bởi lẽ Việt Nam là một quốc gia phát triển nông nghiệp từ sau giai đoạn đổi mới năm 1986 cho đến hiện nay. Theo báo cáo của World bank (2016) về nông nghiệp Việt Nam, tỷ trọng lao động nông nghiệp trong tổng lao động việc làm của Việt Nam năm 2000 là khoảng $65 \%$ và giảm xuống còn $47 \%$ năm 2012 . Có thể thấy lực lượng lao động của Việt Nam vẫn còn tập trung lớn cho lĩnh vực nông nghiệp, và vì vậy đối với phát triển tài chính, lực lượng lao động có ảnh hưởng ngược chiều đến phát triển tài chính.

Biến GDP bình quân đầu người có hệ số hồi quy dương và có tác động tích cực tới phát triển tài chính. Đây là biến có dấu đúng với kỳ vọng ban đầu cũng như phù hợp với kết quả nghiên cứu trước như Kilic và Ozcan (2018).

\subsection{Kết quả chạy hồi quy tác động trong ngắn hạn}

Mô hình hiệu chỉnh sai số ECM được đề xuất bởi Engle và Granger (1987) để xác định tác động ngắn hạn của vốn con người đến phát triển tài chính ở Việt Nam trong giai đoạn 1990 2018. Mô hình tối ưu trong nghiên cứu tác động của vốn con người đến phát triển tài chính ở Việt Nam áp dụng theo phương pháp $\operatorname{ARDL}(1,0,2,2,0)$. 
Theo Bảng 5, hệ số hồi quy của biến $\mathrm{D}(\mathrm{DLIFE})$ âm và có ý nghĩa thống kê ở mức ý nghĩa $1 \%$. Hệ số này âm ở thời kỳ hiện tại và dương ở thời kỳ trước đó. Điều này ngụ ý rằng, trong ngắn hạn tuổi thọ của lao động có tác động ngược chiều với phát triển tài chính ở thời điểm hiện tại, và có tác động tích cực đến phát triển tài chính ở thời kỳ sau đó. Một điều tương tự đối với hệ số hồi quy của biến $\mathrm{D}(\mathrm{DLNPOPU})$ âm và có ý nghĩa thống kê ở mức $1 \%$. Biến dân số lao động trong ngắn hạn có tác động ngược chiều với phát triển tài chính ở thời kỳ hiện tại, và có tác động tích cực đến phát triển tài chính ở thời kỳ sau đó.

\section{Bảng 5}

Tác động trong ngắn hạn của các biến

\begin{tabular}{|c|c|c|c|c|}
\hline Tên biến & Hệ số hồi quy & Sai số chuẩn & Thống kê t & Xác suất \\
\hline $\mathrm{C}$ & 0.172190 & 0.020255 & 8.501245 & 0.0000 \\
\hline $\mathrm{D}$ (DLIFE) & -0.575057 & 0.181435 & -3.169483 & 0.0059 \\
\hline D(DLIFE(-1)) & 0.587961 & 0.185740 & 3.165502 & 0.0060 \\
\hline D(DLNPOPU)) & -622.7735 & 235.1996 & -2.647850 & 0.0175 \\
\hline D(DLNPOPU(-1)) & $1,264.107$ & 245.7465 & 5.143949 & 0.0001 \\
\hline CointEq(-1) & -0.996152 & 0.102539 & -9.714872 & 0.0000 \\
\hline $\mathrm{R}^{2}$ & 0.828494 & \multicolumn{2}{|c|}{ Trung bình biến phụ thuộc } & 0.001445 \\
\hline $\mathrm{R}^{2}$ hiệu chỉnh & 0.785617 & \multicolumn{2}{|c|}{ S.D. biến phụ thuộc } & 0.098342 \\
\hline Sai số phần dư & 0.045534 & \multicolumn{2}{|c|}{ Akaike info criterion } & -3.141538 \\
\hline Tổng bình phương phần dư & 0.041467 & \multicolumn{2}{|c|}{ Schwarz criterion } & -2.851208 \\
\hline Tỷ lệ hàm hợp lý & 46.84000 & \multicolumn{2}{|c|}{ Hannan-Quinn criter } & -3.057934 \\
\hline Thống kê F & 19.32274 & \multicolumn{2}{|c|}{ Durbin-Watson stat } & 2.183123 \\
\hline Xác suất (thống kê F) & 0.000000 & & & \\
\hline
\end{tabular}

Nguồn: Tác giả tổng hợp từ EVIEWS

Cũng theo Bảng 5 hệ số CointEq(-1) là tốc độ tự điều chỉnh $\operatorname{ECM}(-1)=-0.996152$ và có ý nghĩa thống kê ở mức $1 \%$ có thể hiểu rằng một khi có một sự thay đổi nào đó từ các biến số của vốn con người hay có những biến động trong ngắn hạn như sự tăng giảm về số lượng lao động hay sự thay đổi tuổi thọ của lao động sẽ làm cho sự phát triển tài chính lệch khỏi giá trị cân bằng dài hạn, nhưng ngay tại kỳ tiếp theo (trong nghiên cứu này là một năm) sau đó giá trị của những tác động này có xu hướng trở về vị trí cân bằng với tốc độ điều chỉnh về đường cân bằng dài hạn là $99.6152 \%$. Có thể nhận thấy, tốc độ điều chỉnh $\operatorname{ECM}(-1)$ là rất cao, gần như là tuyệt đối khi có các "cú sốc" trong ngắn hạn sẽ làm cho biến phát triển tài chính hợp nhất về điểm cân bằng ở thời kỳ kế tiếp.

\subsection{Các kiểm định cho mô hình}

\section{Bảng 6}

Tổng hợp các kiểm định mô hình

\begin{tabular}{|l|l|}
\hline \multicolumn{1}{|c|}{ Loại kiểm định } & \multicolumn{1}{c|}{ Giá trị } \\
\hline & Obs*R-squared \\
\hline Kiểm định tương quan chuỗi (Breusch-Godfrey) & $2.266 \quad$ (Prob $=0.1322)$ \\
\hline Kiểm định phương sai thay đổi (White test) & $10.415 \quad($ Prob $=0.3179)$ \\
\hline Kiểm định sự phù hợp của mô hình (Ramsey RESET test) & $1.359 \quad$ (Prob $=0.2618)$ \\
\hline Kiểm định phân phối chuẩn (Normality test) & $4.806 \quad$ (Prob $=0.0904)$ \\
\hline
\end{tabular}

Nguồn: Tính toán của tác giả 
Theo Bảng 6 có thể thấy tất cả các kiểm định của mô hình có Prob $>0.05$ nên chấp nhận giả thiết mô hình không gặp phải các khuyết tật phương sai thay đổi, tự tương quan, và mô hình có phần dư theo phân phối chuẩn. Kiểm định CUSUM và CUSUMSQ cho thấy mức độ ổn định của mô hình là đảm bảo khi kiểm định tổng tích lũy hiệu chỉnh của phần dư đều nằm trong dải cộng trừ ứng với mức ý nghĩa 5\% (Hình 2).

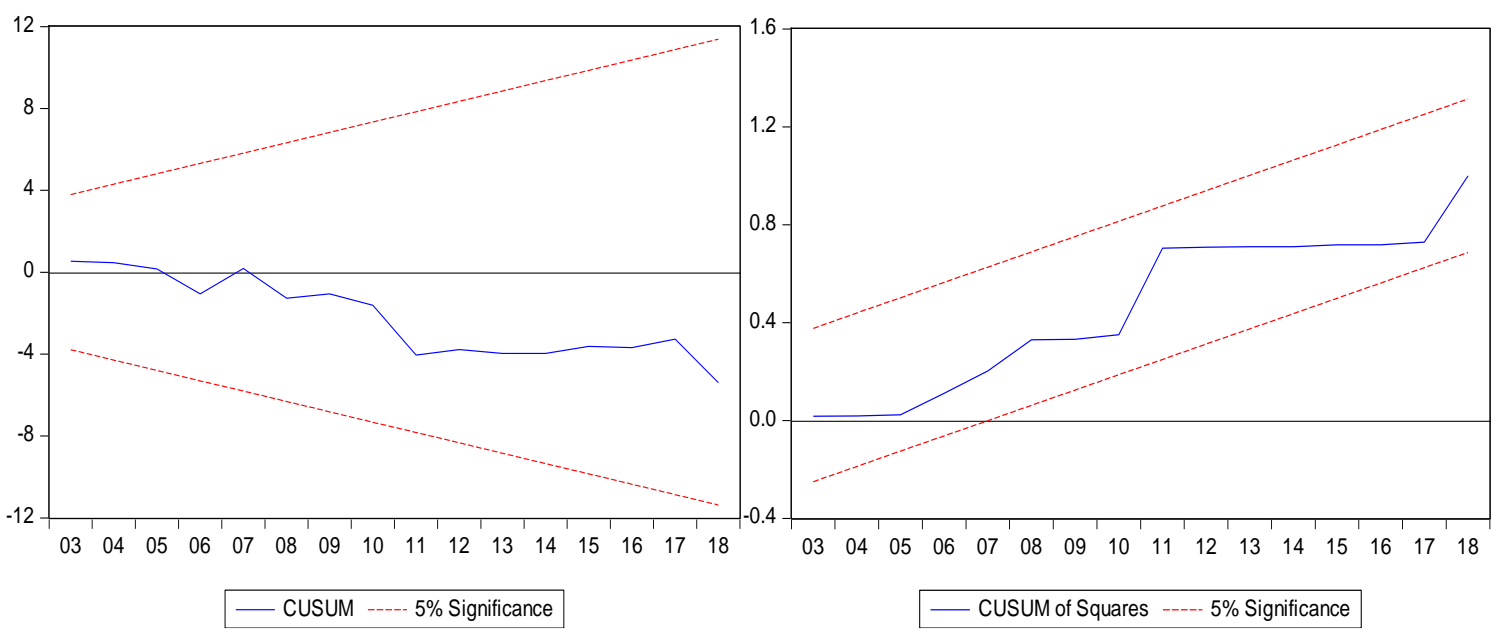

Hình 2. Kết quả kiểm định CUSUM và CUSUMSQ của mô hình

Nguồn: Tác giả tổng hợp từ EVIEWS

\section{Kết luận}

Nghiên cứu tác động của vốn con người đến phát triển tài chính ở Việt Nam trong giai đoạn 1990 - 2018 được triển khai bằng phương pháp định lượng, dữ liệu chuỗi thời gian hằng năm từ năm 1990 - 2018, nguồn dữ liệu thứ cấp được tác giả thu thập từ World bank.

Về mối quan hệ trong ngắn hạn, kết quả hồi quy cho thấy có hai biến độc lập là tuổi thọ của lao động và số lượng lao động có hệ số hồi quy có ý nghĩa thống kê tác động lên biến phát triển tài chính. Các biến này tác động âm đến phát triển tài chính trong năm hiện tại và tác động dương đến phát triển tài chính ở năm trước đó (tức độ trễ $\mathrm{I}(-1)$ ). Theo hiểu biết của tác giả, việc có tác động ngược chiều ở năm hiện tại phản ánh trong ngắn hạn nếu có sự gia tăng về tuổi thọ của lao động hay số lượng lao động tăng đột biến trong năm hiện tại sẽ gây khó khăn cho phát triển tài chính ngay năm đó, bởi lẽ việc tiếp cận đối với các dịch vụ tài chính cần có thời gian để có thể thích nghi được. Kết quả trong ngắn hạn như vậy là phù hợp với kết quả nghiên cứu của Awan và Kamran (2017).

Đối với quan hệ trong dài hạn, kết quả hồi quy cho thấy hệ số hồi quy cả bốn biến tỷ lệ nhập học tiểu học, tuổi thọ của lao động, số lượng lao động và thu nhập bình quân đầu người đều có ý nghĩa thống kê ở mức $5 \%$ tác động đến phát triển tài chính. Có ba biến là tỷ lệ nhập học tiểu học, tuổi thọ của lao động và thu nhập bình quân đầu người có hệ số hồi quy dương với phát triển tài chính. Đây là ba biến có tác động tương đối lớn và ảnh hưởng đến phát triển tài chính của Việt Nam trong giai đoạn 1990 - 2018. Hojo (2003) cho rằng tỷ lệ nhập học giáo dục thúc đẩy tăng trưởng gián tiếp thông qua việc cải thiện năng suất. Vì vậy, tỷ lệ nhập học tiểu học có tác động trong dài hạn đến phát triển tài chính thực sự là phù hợp. Tương tự như tỷ lệ nhập học, tuổi thọ của lao động và thu nhập bình quân đầu người đều có tác động tích cực đến phát triển tài chính về lâu dài. Kết quả của nghiên cứu này phù hợp với kết quả các nghiên cứu trước như Hakeem và Oluitan (2012), Sethi và cộng sự (2019); Zaman, Izhar, Khan, và Ahmad (2012); Zaidi và cộng sự (2019); Đối với biến số lượng lao động, trong dài hạn có tác động âm đến phát 
triển tài chính.

Từ kết quả của nghiên cứu, tác giả đề xuất các khuyến nghị như sau:

Để phát triển tài chính ở Việt Nam thực sự có hiệu quả và ngày càng đi vào chiều sâu, các cơ quan chuyên trách cần thực hiện các khuyến nghị như:

Đối với tỷ lệ nhập học tiểu học, các cơ quan chuyên trách như Bộ Giáo dục đào tạo cần có chính sách thúc đẩy nhiều hơn nữa, trong việc vận động người dân tiếp tục thực hiện đưa trẻ đến trường đúng tuổi quy định, qua đó tiếp tục gia tăng tỷ lệ nhập học bậc tiểu học ở Việt Nam trong thời gian tới.

Về tuổi thọ của lao động, với kết quả của nghiên cứu cũng cho thấy có tác động tích cực đến phát triển tài chính tại Việt Nam. Do đó, trong giai đoạn sắp tới cần có nhiều hơn nữa các chính sách, giải pháp để hỗ trợ, giúp cải thiện tuổi thọ của lao động lên cao hơn.

Đối với số lượng lao động trong các lĩnh vực nông nghiệp, lâm nghiệp thủy sản, nhà nước cần có chính sách phù hợp để giảm bớt tỷ trọng cũng như thâm hụt lao động trong lĩnh vực này nhằm giúp cho lực lượng lao động có cơ hội chuyển sang các ngành nghề liên quan đến xu hướng phát triển thị trường tài chính ở Việt Nam.

Thu nhập bình quân đầu người có ảnh hưởng tích cực đến phát triển tài chính của Việt Nam, bởi lẽ khi thu nhập của người dân ổn định, việc chi tiêu dùng cho các hoạt động tài chính cũng vì vậy mà phát triển hơn. Nhà nước, chính phủ hay các cơ quan chuyên trách như các bộ tài chính, bộ công thương... cần có nhiều quy định cũng như các chính sách hỗ trợ tích cực và nhanh chóng để nhiều công ty chú trọng hơn trong việc hoàn thiện các chương trình, các phần mềm thanh toán, qua đó sẽ giúp cho thị trường tài chính ở Việt Nam ngày càng gia tăng.

\section{LỜI CÁM ƠN}

Nghiên cứu này là một phần trong đề tài nghiên cứu khoa học cấp Bộ.

\section{Tài liệu tham khảo}

Arif, I., \& Khan, L. (2019). The role of financial development in human capital development: Evidence from Pakistan. Pakistan Journal of Commerce and Social Sciences, 13(4), 1029-1040.

Awan, A. G., \& Kamran, M. (2017). Impact of human capital development on Pakistan's economic growth. Global Journal of Management, Social Sciences and Humanities, 3(3), 418-439.

Bardi, W., \& Ayouni, S. E. (2016). Human capital, financial development and economic growth: Empirical evidence from Mediterranean countries. International Research Journal of Finance and Economics, 153, 74-84.

Becker, G. S., \& Murphy, K. M. (2009). Social economics: Market behavior in a social environment. Cambridge, MA: Harvard University Press.

Dickey, D., \& Fuller, W. A. (1981). The likelihood ratio statistics for autoregressive time series with a unit root. Econometrica, 49(4), 1057-1072.

Dinh, H. P., \& Tu, H. D. (2016). Tác động của vốn con người đến tăng trưởng kinh tế Đồng bằng Sông Cửu Long [The impact of human capital on economic growth in the Mekong Delta]. Tạp chí Phát triển Kinh tế, 27(2), 2-16. 
Engle, R. F., \& Granger, C. W. J (1987). Co-integration and error correction: Representation, estimation, and testing. Econometrical, 55(2), 251-276.

Florin, J., \& Schultze, W. (2000). Social capital and fundability of high potential new ventures. Paper presented at the Academy of Management Meetings, Toronto.

Giri, M. S. (2014). The relationship between financial development indicators and human development in India. International Journal of Social Economics, 41(12), 1194-1208.

Gujarati, D. (2003). Basic econometrics (4th ed.). Boston, MA: McGraw-Hill.

Hakeem, M., \& Oluitan, O. (2012). Financial development and human capital in South Africa: A time-series approach. Research in Applied Economics, 4(3), 18-38.

Hatemi-J., A., \& Shamsuddin, M. (2016). The causal interaction between financial development and human development in Bangladesh. Applied Economics Letters, 23(14), 995-998.

Hojo, M. (2003). An indirect effect of education on growth. Economics Letters, 80(1), 31-34.

International Monetary Fund (IMF). (2014). Redistribution, inequality, and growth. Retrieved June 15, 2020, from https://www.imf.org/en/Publications/Staff-DiscussionNotes/Issues/2016/12/31/Redistribution-Inequality-and-Growth-41291

Johansen, S. (1992). Determination of cointegration rank in the presence a linear trend. Oxford Bulletin of Economics and Statistics, 54(3), 383-397.

Johansen, S., \& Juselius, K. (1990). Maximum likelihood estimation and inference on cointegration - with applications to the demnad for money. Oxford Bulletin of Economics and Statistics, 52(2), 169-210.

Khan, Z, Hussain, M., Shabaz, M., Yang, S., \& Jiao, Z. (2020). Natural resource abundance, technological innovation, and human capital nexus with financial development: A case study of China. Resources Policy, 65(1), Article 101585. doi:10.1016/j.resourpol.2020.101585

Kilic, C., \& Ozcan, B. (2018). The impact of financial development on human capital: Evidence from emerging market economies. International Journal of Economics and Financial Issues, 8(1), 258-267.

Laroche, M., Mérette., M., \& Ruggeri, G. C. (1999). On the concept and dimensions of human capital in a knowledge-based economy context. Canadian Public Policy/Analyse De Politiques, 25(1), 87-100.

Le, V. T. (2017). Phát triển tài chính và phương pháp đánh giá: Nghiên cứu đối với trường hợp Việt Nam [Financial development and assessment methods: A case study of Vietnam]. Tạp chí Nghiên cứu Kinh tế, 8(471), 56-64.

Merton, R. C., \& Bodie, Z. (1995). A conceptual framework for analyzing the financial environment. In Chap 1 The Global Financial System: A Functional Perspective (pp. 331). Boston, MA: Harvard Business School Press.

Nafziger, E. W. (2006). Economic development (4th ed.). New York, NY: Cambridge University Press. Nguyen, K. D. (2013). Vai trò vốn con nguời đối với tăng truởng kinh tế các tỉnh, thành phố Duyên hải Nam Trung Bộ giai đoạn 2000-2011 [The role of human capital in economic growth of provinces and cities in the South Central Coast in the 2000-2011 period] (Doctoral dissertation, Open University Ho Chi Minh City, Ho Chi Minh, Vietnam).

Nguyen, T. D. (2014). Nghiên cứu phát triển con người: Quan điểm, xu hướng và những gợi mở [Human development research: Perspectives, trends and implications]. Tạp chí Nghiên cúu Con ngưòi, 1(70), 11-17. 
Nik, A. H., Zahra, S. N., Yunes, S., \& Nima, S. (2013). The relationship between financial development indicators and human capital in Iran. Management Science Letters, 3(4), 1261-1272.

Nik, H. A., Nasab, Z. S., Salmani, Y., \& Shahriari, N. (2013). The relationship between financial development indicators and human capital in Iran. Management Science Letters, 3(4), 1261-1272.

Pesaran, M. H., Shin, Y., \& Smith, R. J. (1996). Testing for the "Existence of a long-run relationship" (DAE working papers amnalgamated series, No. 9622). Cambridge, UK: University of Cambridge.

Pesaran, M. H., Shin, Y., \& Smith, R. J. (2001). Bounds testing approaches to the analysis of level relationships. Journal of Applied Econometrics, 16(3), 289-326.

Satrovic, E. (2017). Financial development and human capital in Turkey: ARDL approach. Cappadocia Academic Review, 1(2), 1-15.

Schultz, T. (1961). Investment in human capital. American Economic Review, 51(1), 101-124.

Sehrawat, M., \& Giri, A. K. (2014). The relationship between financial development indicators and human development in India. International Journal of Social Economics, 41(12), 1194-1208.

Sehrawat, M., \& Giri, A. K. (2017). An empirical relationship between financial development indicators and human capital in some selected Asian coutries. International Journal of Social Economics, 44(3), 337-349.

Sethi, N., Mishra, B. R., \& Bhujabal, P. (2019). Do market size and financial development indicators affect human capital of select south Asian economies? International Journal of Social Economics, 46(7), 887-903.

Tran, L. T. (2014). Thực trạng vốn con người của Việt Nam từ cách tiếp cận về giáo dục [The human capital situation of Vietnam from the approach to education]. In $K y$ yếu công trình khoa hoc 2014 - Phần I [Proceedings of scientific works 2014 - Part I] (pp. 114-123). Hanoi, Vietnam: Trường Đại học Thăng Long.

United Nations Development Programme (UNDP). (2009). Human development report. Retrieved June 20, 2020, from http://hdr.undp.org/sites/default/files/reports/269/hdr_ 2009_en_complete.pdf

World Bank. (2014). Global financial development report 2014: Financial inclusion. Retrieved June 10, 2020, from http://documents.worldbank.org/curated/en/ 225251468330270218/Global-financial-development-report-2014-financial-inclusion

World Bank. (2016). Poverty and shared prosperity 2016: Taking on inequality. Retrieved November 11, 2020, from https://elibrary.worldbank.org/doi/abs/10.1596/978-1-4648-0958-3

World Economic Forum. (2009). Financial development report. Retrieved June 12, 2020, from https://www.weforum.org/reports/financial-development-report-2009

Zaidi, S. A. H., Wei, Z., Gedikli, A., Zafar, M. W., Hou, F., \& Iftikhar, Y. (2019). The impact of globalization, natural resources abundance, and human capital on financial development: Evidence from thirty-one OECD countries. Resources Policy, 64(2019), 1-9.

Zaman, K., Izhar, Z., Khan, M. M., \& Ahmad, M. (2012). The relationship between financial indicators and human development in Pakistan. Economic Modelling, 29(5), 1515-1523. 